\title{
POTENCIAL DO CADASTRO AMBIENTAL RURAL (CAR) NO CONTROLE DO DESMATAMENTO EM ASSENTAMENTOS: UM ESTUDO NO MUNICÍPIO DE NOVO REPARTIMENTO (PA)
}

\author{
Monique Helen Cravo Soares Farias ${ }^{(\mathrm{a})}$, Norma Ely Santos Beltrão ${ }^{(\mathrm{b})}$, Cleber Assis dos Santos ${ }^{(\mathrm{c})}$, \\ Lianne Borja Pimenta ${ }^{(d)}$ \\ (a) Mestre pelo Programa de Pós-Graduação em Ciências Ambientais (PPGCA), Universidade do Estado do Pará, \\ adm.moniquefarias@gmail.com \\ (b) Doutora em Economia Agrícola; Professora do Programa de Pós-Graduação em Ciências Ambientais (PPGCA), \\ Universidade do Estado do Pará \\ (c) Mestrando do Programa de Pós-Graduação em Meteorologia Aplicada, Universidade Federal de Viçosa \\ (d) Mestranda do Programa de Pós-Graduação em Ciências Ambientais (PPGCA), Universidade do Estado do Pará
}

Eixo: Uso e Ocupação das Terras e Legislação Ambiental

\begin{abstract}
Resumo
Ao avaliar a dinâmica do desmatamento em $15 \%$ dos assentamentos federais do Estado do Pará, durante cinco anos, detectou-se haver proporcionalmente mais desmatamentos no interior dos assentamentos do que na área que os circunscreve. Assim, tem-se o Cadastro Ambiental Rural (CAR) como uma contribuição para a compreensão tanto da expansão da fronteira quanto daquilo que na literatura se denomina Uso e Mudança na Cobertura da Terra, oferecendo um meio eletrônico que permite o cruzamento de informações do desmatamento com o mapa fundiário, apresentando a situação das propriedades ou posses rurais e sua relação com cortes na floresta. Este trabalho tem como objetivo analisar a efetividade do CAR como política ambiental em projetos de assentamentos no município de Novo Repartimento, visando compreender os fatores associados ao avanço do desmatamento e as políticas públicas formuladas para contê-lo. Para seu desenvolvimento, foi realizado levantamento bibliográfico, coleta de dados e análise de geoprocessamento.
\end{abstract}

Palavras chave: Legislação. Política. Registro. Regularização

\section{Introdução}

Ao longo das últimas décadas, consideráveis esforços e recursos foram investidos no desenvolvimento sustentável na Amazônia rural. Em geral, estes esforços foram destinados a conservar a paisagem natural da floresta e, ao mesmo tempo, tentar proteger e melhorar o bem-estar das populações locais particularmente a imensa diversidade de grupos indígenas e comunidades tradicionais que vivem na região. Estes objetivos são relevantes não só para as populações locais, mas também a nível mundial, como demonstrado muito claramente pelo atual debate sobre o papel fundamental da Amazônia no futuro do balanço de carbono na mudança climática global (BACCINI et al., 2012; POKORNY, 2013; AGUIAR et al., 2015). 
Sendo a Amazônia Brasileira biogeograficamente heterogênea, os impactos antropogênicos sofridos resultam de uma enorme variedade de padrões de desmatamento associados a diferentes atores e formas de uso da terra. Dada a complexidade e dinâmica desta região, existem muitas iniciativas voltadas ao controle e prevenção do desmatamento (DINIZ et al., 2015; RODRIGUES-FILHO et al., 2015).

Assunção et al. (2015) expõem que as políticas de conservação destinadas a controlar e prevenir o desmatamento na Amazônia passaram por revisões significativas durante os anos 2000, marcadas por dois pontos de grande relevância: o lançamento do Plano de Ação para a Prevenção e Controle do Desmatamento na Amazônia Legal (PPCDAm) em 2004, integrando ações entre diferentes instituições governamentais e introduzindo procedimentos inovadores de controle, monitoramento ambiental e gestão territorial; e a implementação de melhorias na tecnologia de monitoramento e disponibilidade de dados anuais via satélite sobre o desmatamento em escala municipal, possibilitando o estudo de sua dinâmica, o que contribui para a compreensão de como incentivos e políticas moldam a ação do desmatamento (HARGRAVE \& KISKATOS, 2013).

No entanto, de acordo com Pacheco et al. (2010), há uma tensão crescente nas políticas públicas aplicadas pelos governos da Região Amazônica uma vez que, por um lado, algumas políticas tentam facilitar o crescimento econômico relacionado com a promoção do agronegócio, juntamente com maiores investimentos em desenvolvimento de infraestrutura e expansão de uma agricultura mais competitiva ligados aos mercados de exportação; o cumprimento das leis ambientais, cujo objetivo é proteger as florestas e meios de subsistência dos povos locais baseadas no uso dos recursos florestais, e as políticas para conservação de florestas são os instrumentos implementados junto a tentativas de reconhecimento de direitos de posse de povos indígenas locais e outros.

Desde as ondas de migração causadas pelos poderes públicos para sertões amazônicos da década de 1970, quando colonos foram obrigados a desmatar para demonstrar a posse da terra, a política do Brasil passou de uma rápida colonização fronteira aos regimes de reforma agrária, uma estratégia para reverter a tendência de concentração de terras em grandes latifúndios (SCHNEIDER \& PERES, 2015). Caviglia-Harris \& Harris (2011) declaram que os formuladores de políticas na Amazônia brasileira enfrentam o desafio de atender os objetivos ambientais e de desenvolvimento de cidades e vilas que continuam a enfrentar a pressão da migração, resultando em assentamentos projetados de acordo com um modelo que não levava em consideração a paisagem biofísica, as restrições de diferentes regiões biofísicas e os subsequentes impactos ambientais, acarretando impactos negativos na cobertura da terra e transformação do uso da terra. Neste sentido, Song et al. (2015) afirmam que, se resumir em uma lista os processos de uso da terra que muitas vezes são omitidos em muitos ou todos os estudos existentes, os projetos de assentamentos seria um deles. 
Para avaliar essa situação, este trabalho destaca o estado do Pará, o qual detém 1.055 projetos de assentamentos e 221.804 famílias instaladas, constituindo a maior área de assentamentos entre os estados Amazônicos. Em estudo desenvolvido por Calandino et al. (2012), ao avaliar a dinâmica do desmatamento em 15\% dos assentamentos federais do Estado do Pará, durante cinco anos, detectou-se haver proporcionalmente mais desmatamentos no interior dos assentamentos do que na área que os circunscreve. Explica Acselrad (2010) que a construção da Usina Hidrelétrica de Tucuruí, no sul do estado do Pará, inundou, em 1984-1985, $2.600 \mathrm{~km} 2$ de floresta das margens do rio Tocantins, incluindo parte da reserva dos índios Parakanã e alguns núcleos urbanos, deslocando compulsoriamente de suas áreas de moradia e de trabalho cerca de 10 mil famílias.

A inundação do Reservatório de Tucuruí e o processo de relocação geraram indignação na população, que se viu obrigada a viver em acampamentos improvisados ou em superlotados imóveis de Novo Repartimento - núcleo urbano, na época, em implantação (ACSELRAD, 1991). Dedicada, em sua maioria, às atividades extrativas, parte dessa população foi relocada em loteamentos implantados às margens do reservatório. Lançados bruscamente no trabalho agrícola em áreas cuja paisagem natural desconheciam, os relocados não puderam estabilizar-se economicamente, o que favoreceu a reconcentração fundiária e o desmatamento (ACSELRAD, 2010). Atualmente, Novo Repartimento possui 31 projetos de assentamentos rurais, compreendidos em uma área total de 376.767,90 hectares, representando $24,5 \%$ da área total do município.

Este trabalho tem como objetivo analisar a efetividade do Cadastro Ambiental Rural (CAR) como política ambiental em projetos de assentamentos no município de Novo Repartimento, tendo em vista compreender os fatores associados ao avanço do desmatamento e as políticas públicas formuladas para contê-lo, proporcionando o desenvolvimento agrário de forma sustentável.

\section{Metodologia}

\subsection{Descrição da Área de Estudo}

O município de Novo Repartimento integra a Região de Integração (RI) Lago de Tucuruí, localizada na Região Sudeste do Estado do Pará, entrecortada pelo Rio Tocantins e pelas rodovias BR-230 (Rodovia Transamazônica) e PA-150. Abrange uma área de 3.993 .788 hectares, compreendendo também os municípios de Breu Branco, Goianésia do Pará, Itupiranga, Jacundá, Nova Ipixuna e Tucuruí, o que corresponde a aproximadamente 3,20\% do território paraense. Esta região é conhecida por abrigar a Usina Hidrelétrica de Tucuruí (UHT), a qual deu origem a municípios devido ao deslocamento e reassentamento de povoados inteiros, inclusive de aldeias indígenas (para a construção da barragem) e outros cresceram em 
densidade populacional decorrente da atração econômica que o processo de edificação da usina exerceu na época (IDESP, 2013).

Segundo Castro et. al. (2010), e pautados nos dados obtidos no Censo Demográfico 2010 (IBGE), a cidade de Tucuruí exerce a função de pólo regional. Possui a maior população da região, 107.189 habitantes, 27\% da população da região e a maior densidade demográfica com 51,16 habitantes por hectare. O município de Novo Repartimento se destaca em termos de área territorial, com 1.539 .800 hectares, 38,5\% da área territorial total da região, e apresenta a segunda maior população da região. Rocha (2015) expõe que, demograficamente, houve mudança no tamanho, no ritmo de crescimento, na distribuição espacial e na estrutura da população desta região em decorrência da construção da Usina Hidrelétrica de Tucuruí.

No contexto econômico, destaca-se a atuação na área de serviços, indústrias e agropecuária. Novo Repartimento figura entre os dez municípios de maior destaque na produção pecuária que, juntos, respondem por $81 \%$ da produção total do estado. O município de São Félix do Xingu desponta como o de maior rebanho bovino do Pará (2.282.445 cabeças, correspondendo a 11,91\% do rebanho estadual). Chamase atenção para o fato de que Novo Repartimento, $2^{\circ}$ colocado no ranking estadual, possui um rebanho equivalente a $37 \%$ ao daquele município ( 855 mil cabeças), representando $4,46 \%$ do efetivo estadual (FAPESPA, 2015).

O município abriga a Terra Indígena Parakanã, com área de 337.930 hectares, sendo 298.191 hectares de área de florestas em 2014 (88\% de sua área total); apresenta ainda 3 Unidades de Conservação (UC's) e 31 Projetos de Assentamentos (PA's) (IMAZON, 2014).

Para esse estudo, foi dada ênfase aos 31 projetos de assentamentos rurais, compreendidos em uma área total de $376.767,90$ hectares, representando $24,5 \%$ da área total do município (Figura 1). 



Figura 1- Projetos de Assentamentos em Novo Repartimento (PA)

Fonte: IBGE/ INCRA, 2015.

\subsection{Coleta de Dados}

Os aspectos teóricos e conceituais sobre a problemática ambiental em áreas de projetos de assentamentos foram obtidos por meio da análise de artigos científicos nacionais e internacionais, legislações e relatórios e publicações institucionais.

Os dados demográficos da distribuição anual da população nos municípios foram colhidos dos censos demográficos e estimativas intercensitárias, realizados pela Fundação Instituto Brasileiro de Geografia e Estatística (IBGE).

As informações sobre o Cadastro Ambiental Rural (CAR) são oriundas do Sistema Integrado de Monitoramento e Licenciamento Ambiental - Modulo Público (SIMLAM Público), da Secretaria de Estado de Meio Ambiente e Sustentabilidade (SEMAS/PA), e base cartográfica utilizada também foi fornecida pela referida Secretaria.

Os dados sobre o desmatamento na área de estudo foram obtidos através do Portal do Programa de Cálculo do Desmatamento da Amazônia (PRODES/INPE). Esclarecem Piketty et al. (2015) que o método PRODES mede a extensão do desmatamento anual na Amazônia Legal a partir de uma resolução espacial média (tamanho do pixel: 0,36 ha), compreendendo um sistema de classificação baseado na abordagem de modelo de mistura espectral, e usando dados de sensoriamento remoto (imagens de satélite Landsat 5). A 
base de dados espaciais relativa às informações de assentamentos no Estado do Pará e no município de Novo Repartimento foram obtidas do Instituto Nacional da Colonização e Reforma Agrária (INCRA). A partir das bases cartográficas mencionadas, foram selecionados os shapes de cada Plano de Informação (desmatamento, assentamentos e CAR) para o município de Novo Repartimento para, finalmente, realizar análise espacial por geoprocessamento utilizando o Software QGIS 2.8.

\section{Resultados e Discussão}

O município de Novo Repartimento, detentor de 1.539.800 hectares de área, dispõe de 1.183 .160 hectares para regularização por meio do CAR. O número de imóveis rurais cadastrados no Sistema de Monitoramento e Licenciamento Ambiental (SIMLAM) somam 851.176, com uma área cadastrada em torno de $72 \%$ da área total, $72 \%$ da área total cadastrável do município. Uma vez que este ainda não possui o mínimo de $80 \%$ (oitenta por cento) de seu território, excetuadas as unidades de conservação de domínio público e terras indígenas homologadas, com imóveis rurais devidamente monitorados por meio do CAR, não atende as exigências do Ministério do Meio Ambiente, ainda figurando na lista dos municípios que mais desmatam o Bioma Amazônico, mantendo também a classificação de "Município Embargado" junto ao Programa Municípios Verdes, a partir de análises realizadas até o ano de 2016.

A regularização ambiental de propriedades rurais em projetos de assentamentos está prevista no artigo 29 do Código Florestal vigente, realizada através do CAR, definindo ser obrigatório para todos os imóveis rurais, com a finalidade de integrar as informações ambientais das propriedades e posses rurais, compondo base de dados para controle, monitoramento, planejamento ambiental e econômico e combate ao desmatamento.

Nesse sentido, considerando que dos 376.768 hectares de áreas destinadas à formalização de projetos de assentamentos, 308.535 hectares estão disponíveis para regularização ambiental, sendo que 84,5\% desta área cadastrável já está inscrita no sistema do CAR, contabilizada até o ano de 2014.

Os desmatamentos ocorridos em áreas de assentamento são componentes significativos do desmatamento ocorrido no município de Novo Repartimento como um todo, apesar da verificação da redução das taxas de desmatamento a partir de 2008, de acordo com o comparativo a seguir (Tabela I): 
XVII Simpósio Brasileiro de Geografia Fisica Aplicada

I Congresso Nacional de Geografia Física
OS DESAFIOS DA GEOGRAFIA FÍSICA NA FRONTEIRA DO CONHECIMENTO

Instituto de Geociências - Unicamp

Campinas - SP

28 de Junho à 02 de Julho de 2017

Tabela 1- Taxas de Desmatamento no município e nos assentamentos de Novo Repartimento

\begin{tabular}{l|c|c|c|c|}
\hline Ano & $\begin{array}{c}\text { Taxas de } \\
\text { Desmatamento } \\
\text { em Novo } \\
\text { Repartimento } \\
\text { (ha) }\end{array}$ & $\begin{array}{c}\text { \% Relativa à } \\
\text { Área Total do } \\
\text { Município }\end{array}$ & $\begin{array}{c}\text { Taxas de } \\
\text { Desmatamento em } \\
\text { Assentamentos } \\
\text { de Novo Repartimento } \\
\text { (ha) }\end{array}$ & $\begin{array}{c}\text { \% Relativa à Área } \\
\text { Total de } \\
\text { Assentamentos }\end{array}$ \\
\hline 2009 & 29.124 & 1,89 & 17.651 & 4,68 \\
2010 & 21.461 & 1,39 & 12.496 & 3,32 \\
2011 & 18.538 & 1,20 & 10.019 & 2,66 \\
2012 & 12.224 & 0,79 & 8.198 & 2,18 \\
2013 & 15.118 & 0,98 & 10.233 & 2,72 \\
2014 & 7.905 & 0,51 & 4.868 & 1,29 \\
\hline
\end{tabular}

Fonte: PRODES, 2015.

Apesar desse decréscimo, tanto a nível municipal quanto em seus assentamentos, tem-se que os resultados das análises de mudança do uso da terra em assentamentos no período de 2009 a 2014 mostram que 63.465 hectares (16,8\% da área total de assentamentos) de cobertura florestal foram desmatados. Esse quantitativo corresponde a $60,8 \%$ da área total desmatada no município no mesmo período. Essa realidade pode ser referendada pela pesquisa de Barroso \& Alencar (2014), a qual afirma que o significativo número de assentamentos criados com a finalidade de resolver os problemas sociais no campo tem ocasionado consideráveis danos ao meio ambiente, uma vez que os assentados necessitam de área útil à implantação de suas atividades agropecuárias. Foi neste cenário que os assentamentos rurais representaram importante foco de desmatamento.

Com as evidências de que os projetos de assentamentos contribuem com o desmatamento ocorrido no município, além da necessidade em expandir o controle, monitoramento e o combate, procedeu-se a verificação do desenvolvimento do CAR como política pública e seus efeitos sobre o desmatamento nesta categoria fundiária.

A inscrição dos assentamentos de Reforma Agrária no CAR iniciou-se primeiramente com o registro do seu perímetro e posteriormente por meio da individualização dos lotes. Uma vez que se encontra vinculado a fatores sociais e ambientais, o CAR surge como um instrumento de monitoramento, fiscalização e execução em prol da conservação, tendo em vista diagnosticar o passivo ambiental em assentamentos.

Em 2008, no início da vigência do CAR como instrumento da Política de Regularização Ambiental, Novo Repartimento totalizava apenas 1.751 hectares em áreas sob registro no Cadastro Ambiental Rural, correspondendo a $0,14 \%$ da área total cadastrável. 
Já em 2009, verificou-se o início da adesão dos assentados ao Programa do CAR, quando registrou-se 6.853 hectares de área dos projetos de assentamentos de Novo Repartimento inseridos no Sistema de Cadastro Ambiental Rural. A adesão foi crescente nos anos seguintes, chegando ao total de 260.623 hectares, conforme apresentado na tabela 2:

Tabela 2- Evolução do registro do CAR nos assentamentos de Novo Repartimento (PA)

\begin{tabular}{c|c|c|c|}
\hline Ano & $\begin{array}{c}\text { Áreas Inseridas } \\
\text { no CAR (ha) }\end{array}$ & $\begin{array}{c}\text { Áreas Inseridas } \\
\text { no CAR } \\
\text { Acumulado (ha) }\end{array}$ & $\begin{array}{c}\text { \% Relativa à Área } \\
\text { Total de } \\
\text { Assentamentos }\end{array}$ \\
\hline 2009 & 6.853 & 6.853 & $1,82 \%$ \\
2010 & 29.817 & 36.670 & $9,73 \%$ \\
2011 & 10.025 & 46.695 & $12,39 \%$ \\
2012 & 49.206 & 95.901 & $25,45 \%$ \\
2013 & 73.548 & 169.449 & $44,97 \%$ \\
2014 & 91.174 & 260.623 & $69,17 \%$ \\
\hline
\end{tabular}

Fonte: SEMAS, 2015.

Enquanto política de regularização ambiental e de combate ao desmatamento, infere-se que a grande quantidade de propriedades rurais (2.213) inscritos no Sistema do CAR, representando uma área de 69,17\% do total de áreas dos assentamentos rurais de Novo Repartimento em 2014 permite o monitoramento e acompanhamento das atividades de uso da terra desenvolvidas pelos assentados rurais.

Ressalta-se aqui a importância da informação espacial fornecida pelo CAR. O registro por meio do CAR fornece informações essenciais sobre os imóveis rurais localizados em assentamentos, subsidiando assim ações preventivas, fiscalizatórias e punitivas por parte dos órgãos ambientais, tendo em vista a diminuição do passivo ambiental e conservação florestal. Informações como áreas de RL e APPs disponibilizadas pelo CAR são úteis para monitorar o desmatamento nessas áreas especiais e protegidas por lei, e também são capazes de subsidiar o planejamento de ações de políticas de conservação e de eventuais programas de pagamentos por serviços ambientais. Dados relativos ao uso alternativo do solo (UAS) poderiam também ser utilizados em conjunto com dados de produção agropecuária para dimensionar a agricultura familiar nestas áreas, bem como a proposição de alternativas logísticas para melhor armazenamento e distribuição dos produtos originários de assentamentos rurais. 




Conforme verificado na figura 2, no primeiro ano em análise, a adesão foi tímida, tendo uma forte adesão nos anos seguintes, especialmente 2010, 2013 e 2014, sendo que nestes últimos pode ter sido devido à grande mobilização que órgãos federais e estaduais, além de ONGs voltadas ao tema ambiental, fizeram para incentivar a adesão ao CAR. Além da vigência do Novo Código Florestal, que prevê o CAR como instrumento de Política Pública Ambiental, muitos proprietários rurais dentro e fora dos assentamentos rurais começaram a perceber os benefícios de ter o registro do CAR de sua propriedade.
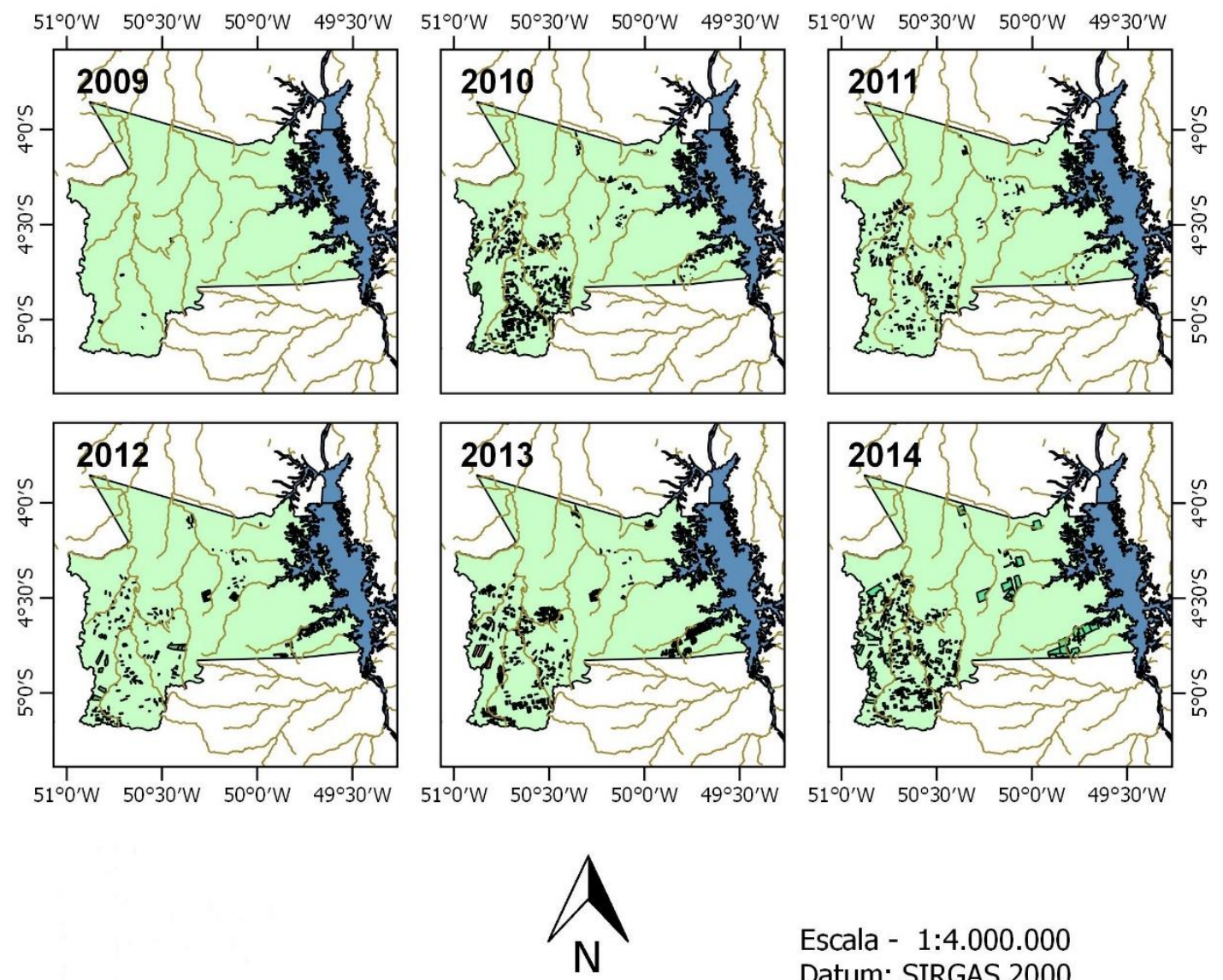

\section{Legenda}

- Rios

Novo Repartimento
Escala - 1:4.000.000

Datum: SIRGAS 2000

Fonte: Base vetorial SEMAS-PA

Ano: 2015

Elaboração: autores

Figura 2- Evolução do CAR em Assentamentos de Novo Repartimento (2009-2014) 
XVII Simpósio Brasileiro

de Geografia Fisica Aplicada

I Congresso Nacional

de Geografia Física
OS DESAFIOS DA GEOGRAFIA FÍSICA NA FRONTEIRA DO CONHECIMENTO

Instituto de Geociências - Unicamp

Campinas - SP

28 de Junho à 02 de Julho de 2017

Assim, para verificar a efetividade do Cadastro Ambiental Rural (CAR) como política ambiental em projetos de assentamentos, iniciou-se a análise da incidência do desmatamento em áreas com e sem o registro do CAR, conforme demonstrado na tabela 3, cujos valores foram obtidos a partir de análises de geoprocessamento:

Tabela 3- Desmatamento em Áreas de Assentamentos Com e Sem CAR

\begin{tabular}{l|c|c|c|c|c|c}
\hline \multicolumn{7}{|c}{ Desmatamento } \\
\cline { 5 - 8 } Ano & $\begin{array}{c}\text { Com CAR } \\
\text { Área Inserida } \\
\text { no CAR (ha)- } \\
\text { Acumulado }\end{array}$ & $\begin{array}{c}\text { Em Áreas de } \\
\text { assentamento } \\
\text { (ha) }\end{array}$ & $\begin{array}{c}\text { Em áreas de } \\
\text { assentamento } \\
\text { cadastradas } \\
\text { (ha) }\end{array}$ & $\begin{array}{c}\text { \% } \\
\text { Relativa }\end{array}$ & $\begin{array}{c}\text { Em áreas de } \\
\text { assentamento } \\
\text { não } \\
\text { cadastradas } \\
\text { (ha) }\end{array}$ & $\begin{array}{c}\text { \% } \\
\text { Relativa }\end{array}$ \\
\hline 2009 & 6.853 & 17.651 & 13 & $0.07 \%$ & 17.638 & $99,93 \%$ \\
\hline 2010 & 36.670 & 12.496 & 1.491 & $11,93 \%$ & 11.005 & $88,07 \%$ \\
\hline 2011 & 46.695 & 10.019 & 1.789 & $17,86 \%$ & 8.230 & $82,14 \%$ \\
\hline 2012 & 95.901 & 8.198 & 2.175 & $26,53 \%$ & 6.023 & $73,47 \%$ \\
\hline 2013 & 169.449 & 10.233 & 5.881 & $57,47 \%$ & 4.352 & $42,53 \%$ \\
\hline 2014 & 260.623 & 4.868 & 2.831 & $58,16 \%$ & 2.037 & $41,84 \%$ \\
\hline
\end{tabular}

Fonte: PRODES/ SEMAS-PA, 2015.

No período analisado foi possível observar reduções sucessivas nas taxas de desmatamento ocorridas em áreas de assentamentos. Os assentamentos, apesar de exercerem grande influência em relação ao desmatamento da região, não são os únicos agentes responsáveis. Com efeito, análises da sua contribuição para a dinâmica anual do desmatamento mostram que, mesmo aumentando em número e em área, eles têm acompanhado a mesma tendência de queda que vem ocorrendo na Amazônia, no Estado e no município como um todo.

Da mesma forma que as taxas de desmatamento foram decrescendo, a adesão ao CAR foi aumentando, conforme mostra a tabela 3. Com os dados de áreas inseridas no CAR e as ocorrências de desmatamento ano a ano, foi possível estimar a sua proporção ocorrida em áreas inseridas no CAR, a fim de avaliar sua efetividade como política ambiental de regularização ambiental.

Assim, as áreas de assentamentos rurais inseridas no CAR totalizaram até o ano de 2014, 260.623 ha. Ocorrências de desmatamento medidas pelo PRODES/INPE no período de 2009 a 2014 foram registradas em áreas com e sem CAR. Vale ressaltar que ocorreu uma adesão gradativa do CAR no período em análise, o que refletiu nos valores percentuais relativos ao total de desmatamento registrado, os quais foram 
crescendo na medida que mais áreas estavam cadastradas, aumentando, portanto, a probabilidade de que os desmatamentos ocorressem em áreas com CAR.

No ano de 2014, do total de área desmatada em áreas de assentamentos, 58,16\% foram em áreas com CAR, e 41,84\% em áreas não registradas. Embora a princípio, esperava-se que as áreas com CAR tivessem menores incidências de desmatamento, dados apontaram uma ocorrência maior em áreas com CAR. Como possível justificativa, tem-se que as áreas que tiveram maior adesão ao CAR, foram aquelas que mais precisavam regularizar suas atividades rurais, as quais muitas vezes prescindiam de modificações no uso da terra, para adequação às atividades de agricultura ou pecuária.

Neste contexto, as mudanças no uso e cobertura da terra, notadamente o desmatamento ocorrido nas áreas de assentamento, podem estar associadas às atividades próprias de assentamentos rurais economicamente produtivos. Além disso, o CAR oferece a possibilidade de certificar as propriedades rurais que comercializam produtos agrícolas, pois só estarão aptas aquelas que estiverem de acordo com a legislação ambiental brasileira, a qual proíbe desmatamento sem licenciamento.

De fato, políticas estaduais tais como o Plano de Prevenção, Controle e Alternativas ao Desmatamento do Estado do Pará (PPCAD-PARÁ), o Acordo pelo Desmatamento Zero firmado com o Ministério Público Federal e o Programa Municípios Verdes, tem incentivado a atividade rural ambientalmente sustentável e tem ajudado a consolidar o CAR como ferramenta de diagnóstico do passivo ambiental em propriedades rurais, atuando assim na fiscalização e conservação do meio ambiente.

\section{Considerações Finais}

A partir do desenvolvimento desta pesquisa, pôde-se verificar que os processos de mudança do uso da terra, particularmente o desmatamento, em áreas de projetos de assentamentos agrários tem significativa contribuição ao total registrado para o município de Novo Repartimento.

A partir da detecção que, no período de 2009 a 2014, 63.465 hectares de desmatamentos ocorreram em áreas de assentamentos, tem-se associado os projetos de Reforma Agrária como um dos principais responsáveis pelo processo de conversão florestal no município.

Entretanto, constatou-se um esforço quanto à regularização ambiental dessas áreas, verificado a partir do crescimento na adesão dos assentados ao Cadastro Ambiental Rural. No ano de 2009, os assentamentos de Novo Repartimento detinham apenas 6.853 hectares em áreas registradas através do Cadastro Ambiental Rural (CAR), correspondendo a 0,14\% da área total cadastrável; já em 2014, o número de áreas cadastradas subiu para 260.623 hectares, sendo que 91.174 hectares em áreas de assentamentos, representando 69,17\% de sua área total. 
Também é importante ressaltar que o reforço de políticas estaduais, tais como o Plano de Prevenção, Controle e Alternativas ao Desmatamento do Estado do Pará (PPCAD-PARÁ), o Acordo pelo Desmatamento Zero firmado com o Ministério Público Federal e o Programa Municípios Verdes, fortaleceram o desenvolvimento do CAR como ferramenta de diagnóstico do passivo ambiental em propriedades rurais, atuando assim na fiscalização e conservação do meio ambiente.

Assim, pode-se definir o CAR como um instrumento importante de gestão ambiental rural, atuando no controle, monitoramento e o combate ao desmatamento em assentamentos no município de Novo Repartimento, mas não é possível declarar que a ocorrência desse desmatamento é ilegal, sendo necessário assim estudos futuros que analisem onde ocorre as maiores incidências.

Neste trabalho, a análise espacial desenvolvida a partir de dados vetoriais foi fundamental para o desenvolvimento de análises de múltiplos dados espaciais, permitindo assim o acesso integrado de várias informações relevantes. Estas combinações permitiram analisar os padrões espaciais de desmatamento, áreas de assentamentos e realização do CAR no município analisado.

\section{Bibliografia}

ACSELRAD, H. Planejamento autoritário e desordem socioambiental na Amazônia: crônica do deslocamento de populações em Tucuruí. Revista de Administração Pública, v. 25, n. 4, p. 53-68, 1991.

ACSELRAD, H. Mercado de terras e meio ambiente em áreas de grandes projetos de investimento: o caso da Usina Hidrelétrica de Tucuruí. Estudos Sociedade e Agricultura, v. 2, 2010.

AGUIAR, A. P. D.; VIEIRA, I. C. G.; ASSIS, T. O.; DALLA NORA, E. L.; TOLEDO, P. M.; SANTOS-JÚNIOR, R. A. O.; BATISTELlA, M.; COELHO, A. S.; KAWAKAMI, E. S.; ARAGÃO, L. E. O. C.; NOBRE, C. A.; OMETTO, J. P. Land use change emission scenarios: anticipating a forest transition process in the Brazilian Amazon?. Global change biology, 2015.

ASSUNÇÃO, J.; GANDOUR, C.; PESSOA, P.; ROCHA, R. Deforestation Scale and Farm Size: The Need for Tailoring Policy in Brazil. Rio de Janeiro: Climate Policy Initiative, 2015, 29 p.

BACCINI, A.; GOETZ, S. J.; WALKER, W. S.; LAPORTE, N. T.; SUN, M.; SULLA-MENASHE, D.; HACKLER, J.; BECK, P. S. A.; DUBAYAH, R.; FRIEDL, M. A.; SAMANTA, S. HOUGHTON, R. A. Estimated carbon dioxide emissions from tropical deforestation improved by carbon-density maps. Nature Climate Change, v. 2, n. 3, p. 182185,2012

BARROSO, L. A.; ALENCAR, G. V. O Cadastro Ambiental Rural (CAR) como instrumento de regularização ambiental em assentamentos de reforma agrária. Revista Brasileira de Gestão Ambiental e Sustentabilidade, v. 1, n. 1, p. 5-13, 2014.

CALANDINO, D.; WEHRMANN, M.; KOBLITZ, R. Contribuição dos assentamentos rurais no desmatamento da Amazônia: um olhar sobre o Estado do Pará. Desenvolvimento e Meio ambiente, v. 26, 2012.

CASTRO, E. R.; MARIN, R. A.; SZLAFSZTEIN, C.; COSTA, E. J. M.; RAVENA, N.; ROCHA, G. M.; ANDRADE, L. G.; SILVA, I. M. C.; FERNANDES, F. A. Estudo Socioeconômico dos Municípios da Região de Tucuruí, Pará. Papers NAEA, n. 258, 2010.

CAVIGLIA-HARRIS, J.; HARRIS, D. The impact of settlement design on tropical deforestation rates and resulting land cover patterns. Agricultural and Resource Economics Review, v. 40, n. 3, p. 451, 2011. 




DINIZ, F. H.; KOK, K.; HOOGSTRA-KLEIN, M. A.; ARTS, B. Mapping future changes in livelihood security and environmental sustainability based on perceptions of small farmers in the Brazilian Amazon. Ecology and Society, v. 20 , n. 2, p. 26, 2015.

FUNDAÇÃO AMAZÔNIA DE AMPARO A ESTUDOS E PESQUISAS DO PARÁ. Boletim Agropecuário do Estado do Pará 2015. Belém: FAPESPA, 2015, 38 p.

HARGRAVE, J.; KIS-KATOS, K. Economic causes of deforestation in the Brazilian Amazon: a panel data analysis for the 2000s. Environmental and Resource Economics, v. 54, n. 4, p. 471-494, 2013.

INSTITUTO DE DESENVOLVIMENTO ECONÔMICO, SOCIAL E AMBIENTALDO PARÁ (IDESP). Indicadores de Qualidade Ambiental dos Municípios da Região de Integração Lago de Tucuruí. Belém: IDESP, 2013, 44 p.

INSTITUTO DO HOMEM E MEIO AMBIENTE DA AMAZÔNIA (IMAZON). Desmatamento e degradação florestal em Novo Repartimento- Pará. Belém: IMAZON, 2014, 2 p.

PACHECO, P.; AGUILAR-STOEN, M.; BÖRNER, J.; ETTER, A.; PUTZEL, L.; DIAZ, M. D. C. V. Landscape transformation in tropical Latin America: assessing trends and policy implications for REDD+. Forests, v. 2, n. 1, p. 1-29, 2010.

PARÁ. Decreto $\mathbf{N}^{\mathbf{0}}$ 1.697, de 5 de Junho de 2009. Institui o Plano de Prevenção, Controle e Alternativas ao Desmatamento do Estado do Pará, e dá outras providências. Diário Oficial do Estado do Pará, № 31435 , de 08 de junho de 2009.

PIKETTY, M. G.; DRIGO, I.; SABlAYROLlES, P.; AQUINO, E. A.; PENA, D.; SIST, P. Annual Cash Income from Community Forest Management in the Brazilian Amazon: Challenges for the Future. Forests, v. 6, n. 11, p. 42284244, 2015.

POKORNY, B. Smallholders, forest management and rural development in the Amazon. New York: Routledge, 2013, 248 p.

ROCHA, G. M. Usinas Hidrelétricas e Mudanças Demográficas na Amazônia Brasileira. Revista Eletrônica de Geografia Austral, v. 7, n. 1, 2015.

RODRIGUES-FILHO, S.; VERBURG, R.; BURSZTYN, M.; LINDOSO, D.; DEBORTOLI, N.; VILHENA, A. M. Election-driven weakening of deforestation control in the Brazilian Amazon. Land Use Policy, v. 43, p. 111-118, 2015.

SCHNEIDER, M.; PERES, C. A. Environmental Costs of Government-Sponsored Agrarian Settlements in Brazilian Amazonia. PloS one, v. 10, n. 8, 2015.

SONG, X. P.; HUANG, C.; SAATCHI, S. S.; HANSEN, M. C.; TOWNSHEND, J. R. Annual Carbon Emissions from Deforestation in the Amazon Basin between 2000 and 2010. PloS one, v. 10, n. 5, 2015. 